\title{
Polyketide Folding in Higher Plants: Biosynthesis of the Phenylanthraquinone Knipholone
}

Gerhard Bringmann, ${ }^{+} *$ Torsten F. Noll, ${ }^{+}$Tanja Gulder, ${ }^{+}$Michael Dreyer, ${ }^{+}$Matthias Grüne, ${ }^{\ddagger}$ and Detlef Moskau ${ }^{\perp}$

${ }^{\ddagger}$ Institute of Organic Chemistry, University of Würzburg, Am Hubland, D-97074 Würzburg,

${ }^{\perp}$ Germany and Bruker BioSpin AG, Industriestrasse 26, CH-8117 Fällanden, Switzerland

\section{TABLE OF CONTENTS:}

- General

- NMR Spectroscopy

- ${ }^{1} \mathrm{H}$ NMR Spectrum of Knipholone (4a) Isolated after Feeding of $\left[{ }^{13} \mathrm{C}_{2}\right]$-Labeled Acetat to K. pumila.

- ${ }^{13} \mathrm{C}$ NMR Spectrum of Knipholone (4a) Isolated after Feeding of $\left[{ }^{13} \mathrm{C}_{2}\right]$-Labeled Acetate to K. pumila.

- 2D INADEQUATE NMR Spectrum of Knipholone (4a) Isolated after $\begin{array}{ll}\text { Feeding of }\left[{ }^{13} \mathrm{C}_{2}\right] \text {-Labeled Acetate to K. pumila } & \mathrm{S} 6 / 7\end{array}$

- ${ }^{1}$ H NMR Spectrum of 8

- ${ }^{13} \mathrm{C}$ NMR Spectrum of $\mathbf{8}$

- $\quad{ }^{1} \mathrm{H}$ NMR Spectrum of $\mathbf{6 a}$

- ${ }^{13} \mathrm{C}$ NMR Spectrum of $\mathbf{6 a}$ 
- ${ }^{1} \mathrm{H}$ NMR Spectrum of $\mathbf{6 b}$

- ${ }^{13} \mathrm{C}$ NMR Spectrum of $\mathbf{6 b}$

- Sketches of the ${ }^{13}$ C NMR Spectrum of Knipholone (4a) after Feeding of (6a) $\quad$ S14 
General. Melting points were determined with a Kofler melting point apparatus and are uncorrected. Optical rotations were measured on a Jasco P-1020 polarimeter, IR spectra were taken on a Jasco FT-IR 460 spectrometer. Mass spectra (EI) were measured on a Finnigan MAT 8200 mass spectrometer at $70 \mathrm{eV}$. NMR data were recorded on a Bruker Avance 500 spectrometer equipped with a cryoprobe, on a Bruker Avance 400, and on a Bruker DMX 600 spectrometer, which in the final stage of the work (experiments with advanced precursors) was also operated with a cryoprobe. $\left(\mathrm{CD}_{3}\right)_{2} \mathrm{CO}(\delta 2.05$ and 29.9$), \mathrm{CDCl}_{3}$ ( $\delta 7.24$ and 77.2), and $\mathrm{CD}_{3} \mathrm{OD}(\delta 3.31$ and 49.2$)$ were used as solvents and internal ${ }^{1} \mathrm{H}$ and ${ }^{13} \mathrm{C}$ standards. Thin-layer chromatography (TLC) was performed on aluminum plates precoated with silica gel 60F-254 as the absorbent. The developed plates were exposed to UV light (254 nm). Column chromatography was performed using silica gel 60 (230-400 mesh).

NMR Spectroscopy. ${ }^{1} \mathrm{H},{ }^{13} \mathrm{C}$, and 2D INADEQUATE spectra were measured using a $5 \mathrm{~mm}{ }^{13} \mathrm{C} /{ }^{1} \mathrm{H}$ cryoprobe at 500 or $600 \mathrm{MHz},{ }^{1} \mathrm{H}^{-13} \mathrm{C}$ HMBC with an inverse $5 \mathrm{~mm}{ }^{1} \mathrm{H} /{ }^{13} \mathrm{C} /{ }^{15} \mathrm{~N}$ cryoprobe at $500 \mathrm{MHz}$ and an inverse ${ }^{1} \mathrm{H} /{ }^{13} \mathrm{C} /{ }^{15} \mathrm{~N}$ cryoprobe on $600 \mathrm{MHz}$ and the 1D SELINQUATE with a $5 \mathrm{~mm}{ }^{13} \mathrm{C} /{ }^{1} \mathrm{H}$ probe at the DMX 600 spectrometer. For all NMR experiments the standard Bruker pulse sequences were used. Coupling constants $(J)$ are reported in $\operatorname{Hertz}(\mathrm{Hz})$.

In the ${ }^{13} \mathrm{C}$ NMR spectrum the carbon atoms were assigned by HMBC correlations (optimized for ${ }^{n} J_{\mathrm{C}, \mathrm{H}}=8 \mathrm{~Hz}$ ). The pairs of coupling carbon atoms were determined by a $2 \mathrm{D}$ INADEQUATE experiment (optimized for ${ }^{1} J_{\mathrm{C}, \mathrm{C}}=60 \mathrm{~Hz}$ ) and confirmed by calculation of their specific double-quantum frequencies (DQF) and by comparison of their ${ }^{1} J_{\mathrm{C}, \mathrm{C}}$ coupling constants. The selective excitation in the SELINQUATE experiment (optimized for ${ }^{1} J_{\mathrm{C}, \mathrm{C}}=67$ $\mathrm{Hz}$ ) was carried out by a $270^{\circ}$-Gauss pulse of $7 \mathrm{~ms}$ length. 


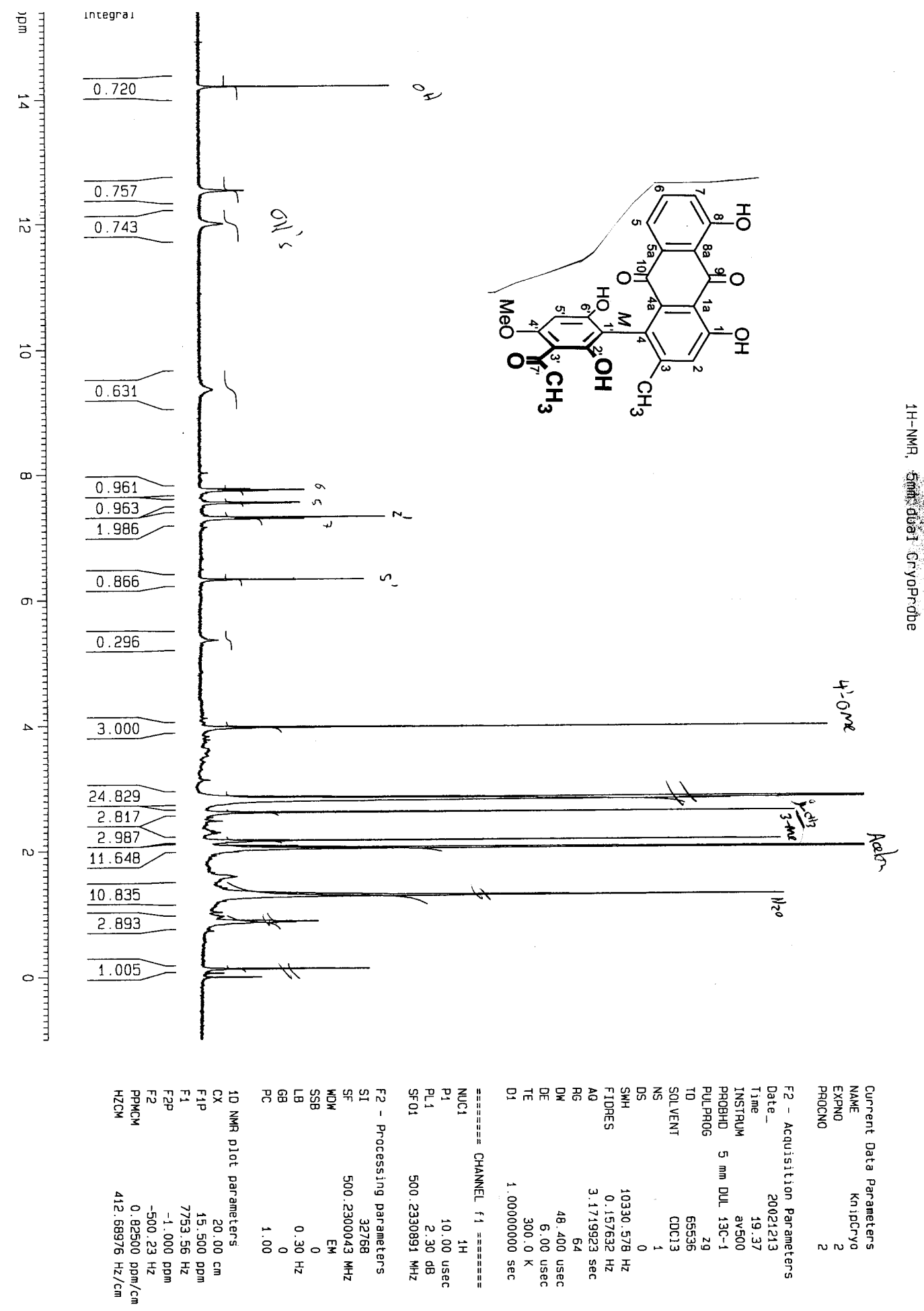

${ }^{1} \mathrm{H}$ NMR Spectrum of Knipholone (4a) Isolated after Feeding $\left[{ }^{13} \mathrm{C}_{2}\right]$-Labeled Acetate to $K$. pumila. 

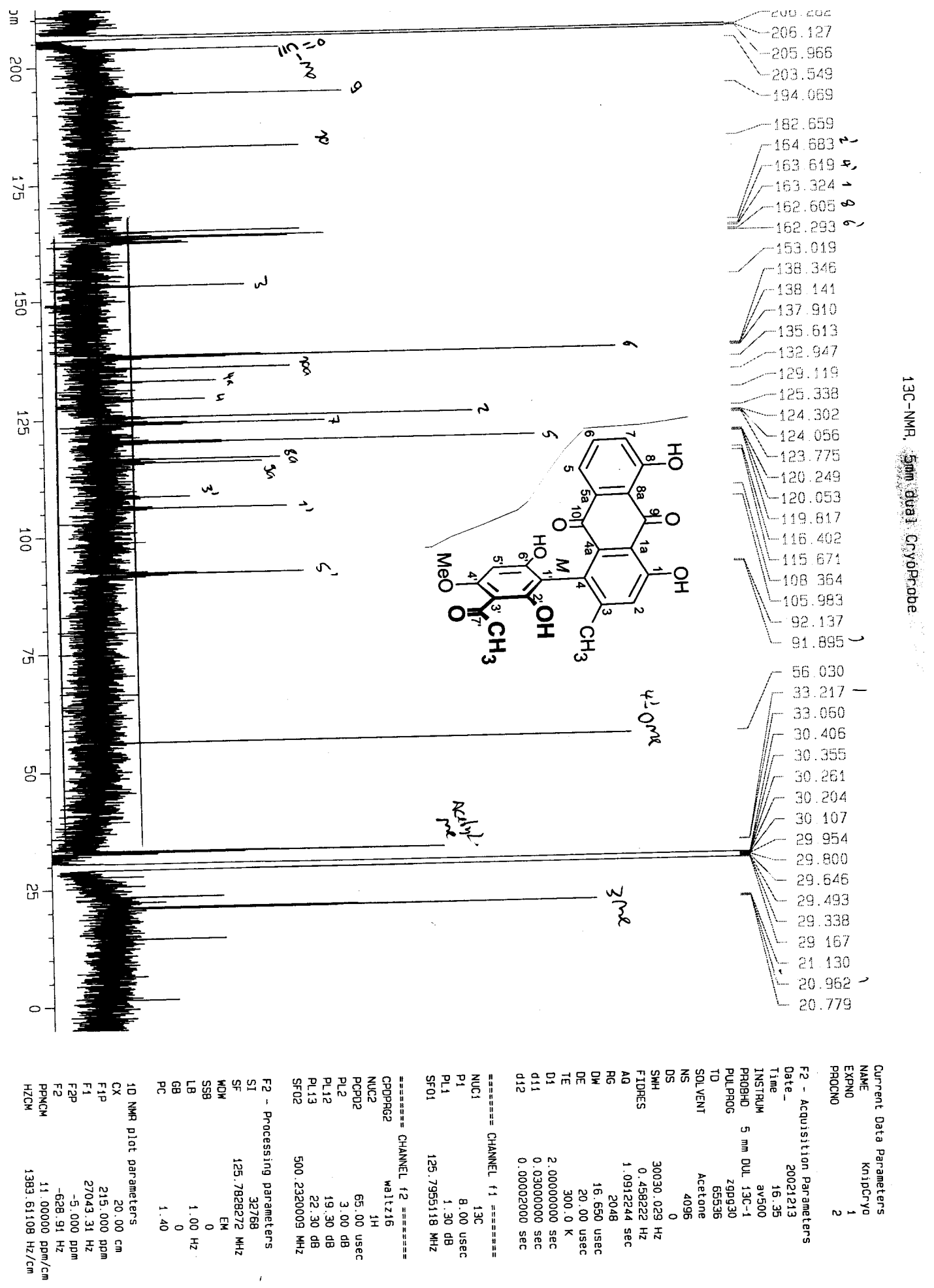

${ }^{13} \mathrm{C}$ NMR Spectrum of Knipholone (2a) Isolated after Feeding of $\left[{ }^{13} \mathrm{C}_{2}\right]$-Labeled Acetate to $K$. pumila. 


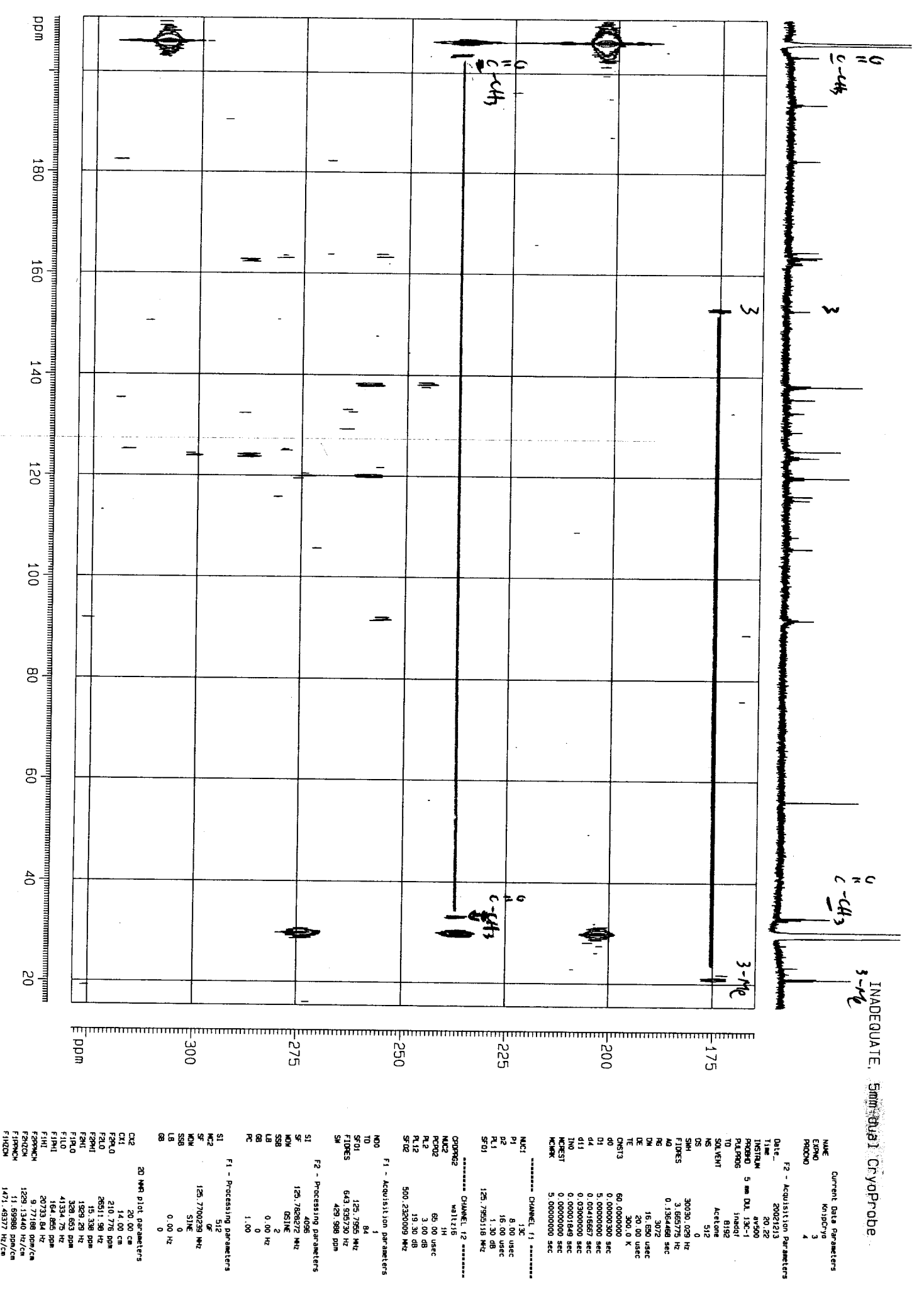

2D INADEQUATE NMR Spectrum of Knipholone (4a) Isolated after Feeding of $\left[{ }^{13} \mathrm{C}_{2}\right]-$ Labeled Acetate to K. pumila. 


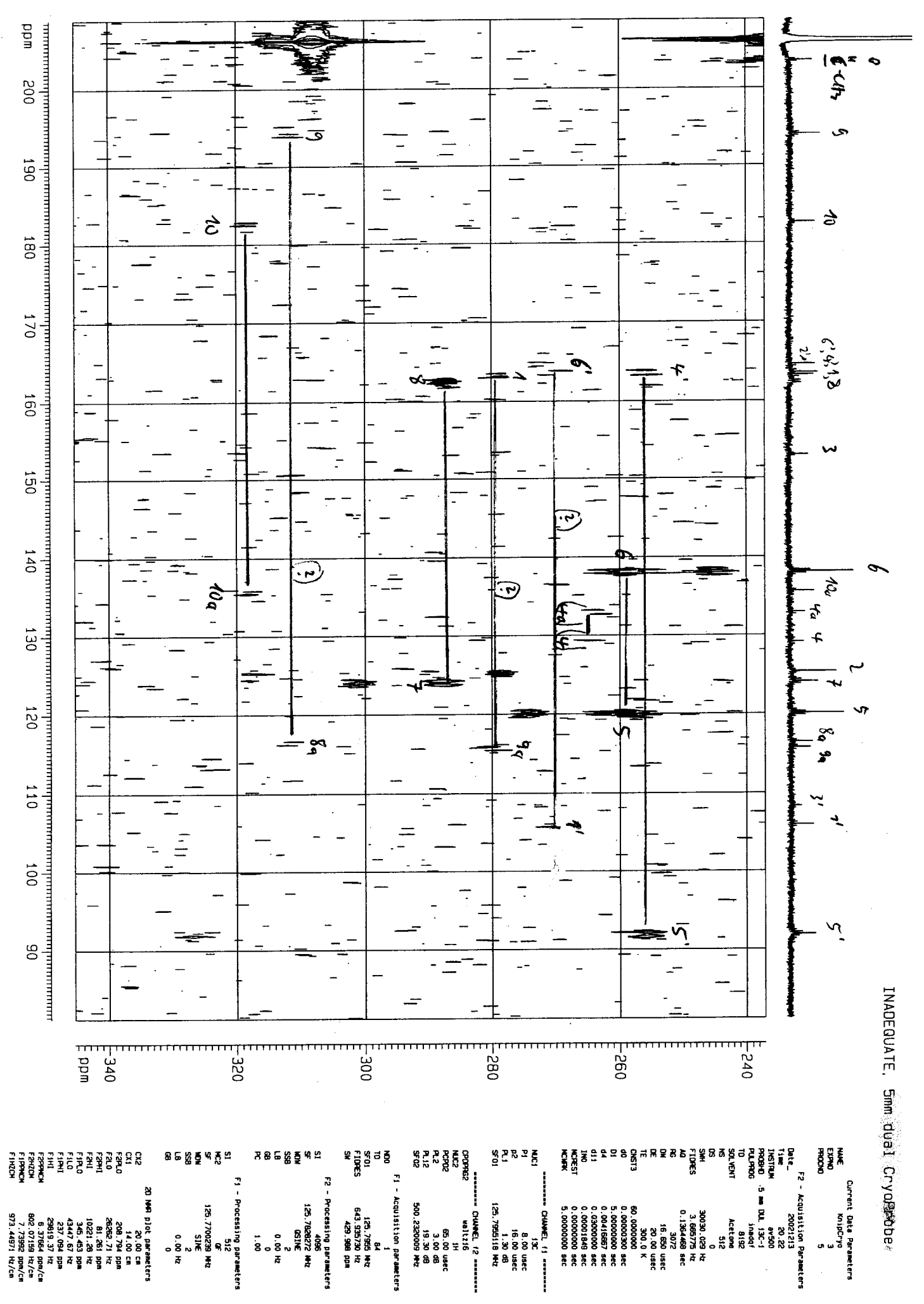

2D INADEQUATE NMR Spectrum of Knipholone (4a) Isolated after Feeding of $\left[{ }^{13} \mathrm{C}_{2}\right]-$ Labeled Acetate to K. pumila. 


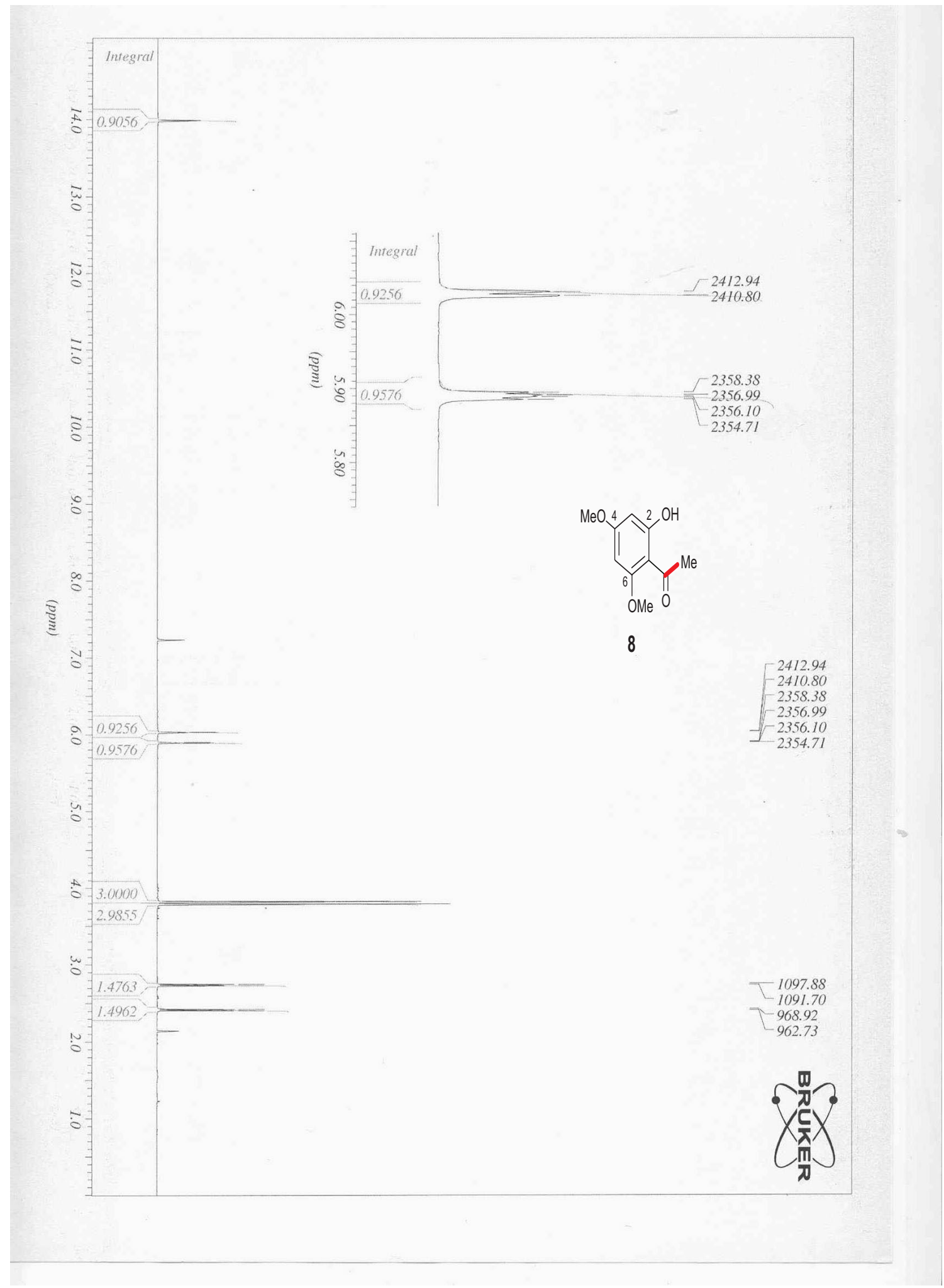

${ }^{1} \mathrm{H}$ NMR Spectrum of $\mathbf{8}$. 


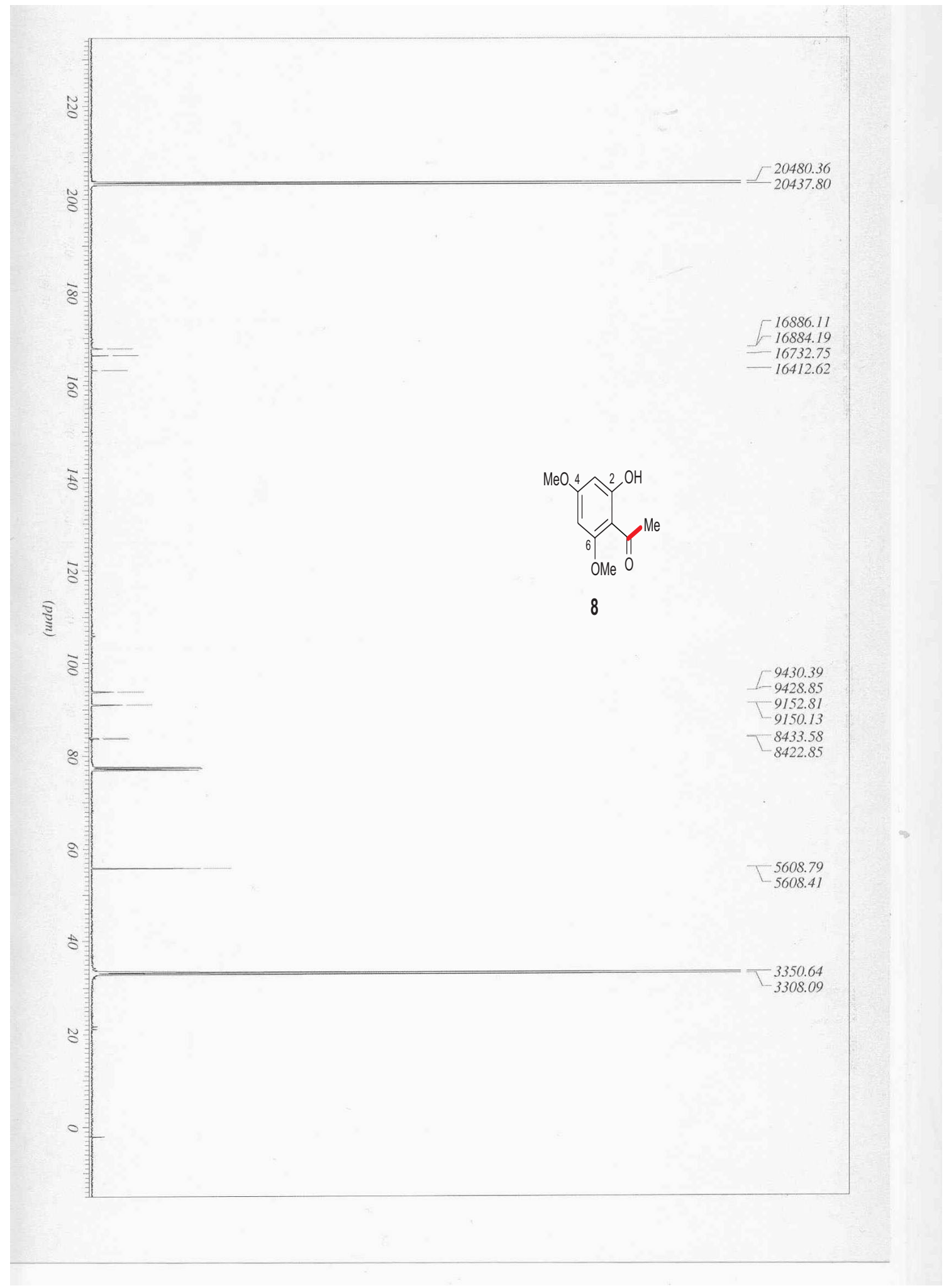

${ }^{13}$ C NMR Spectrum of 8 . 


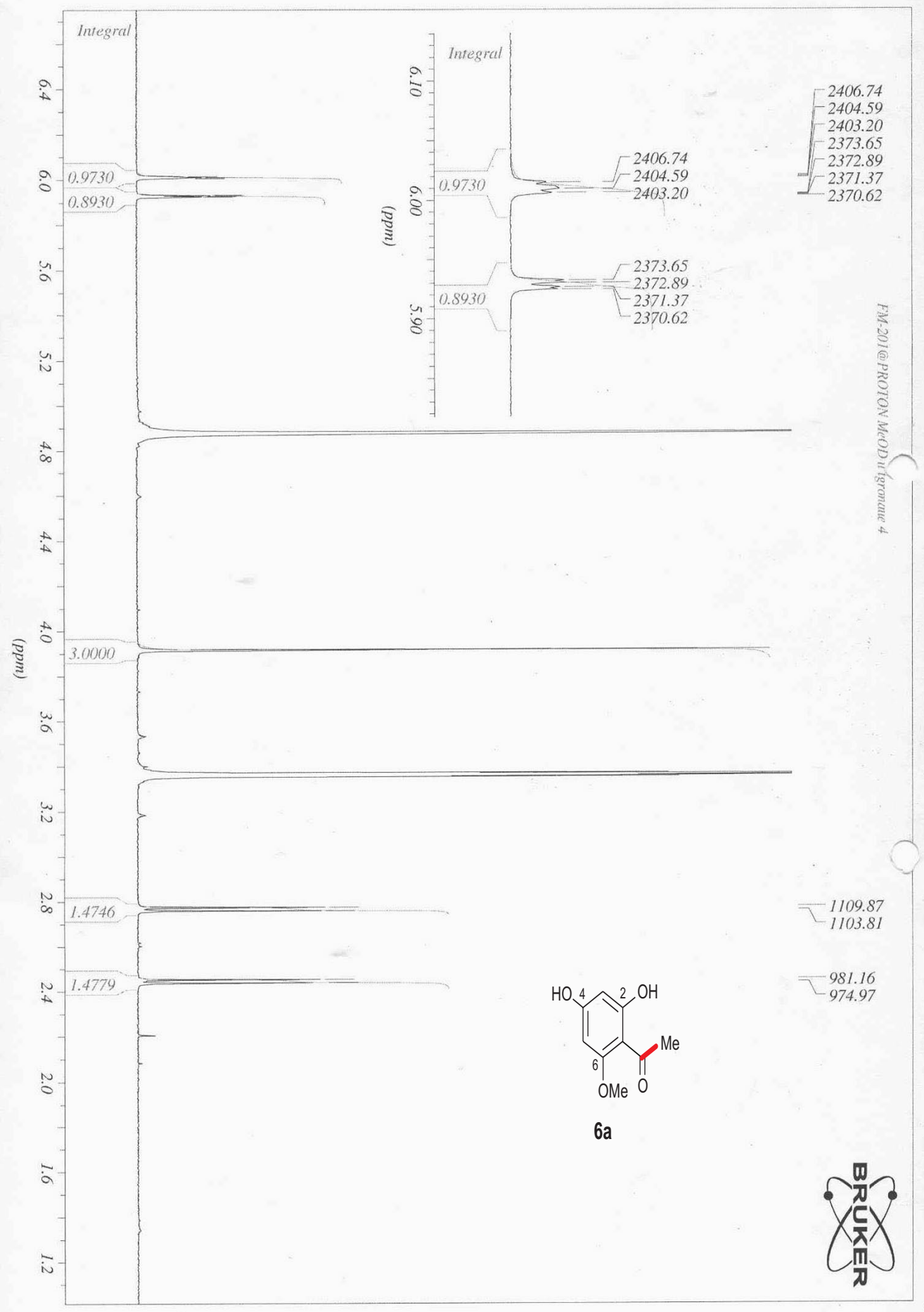

${ }^{1} \mathrm{H}$ NMR Spectrum of $\mathbf{6 a}$. 


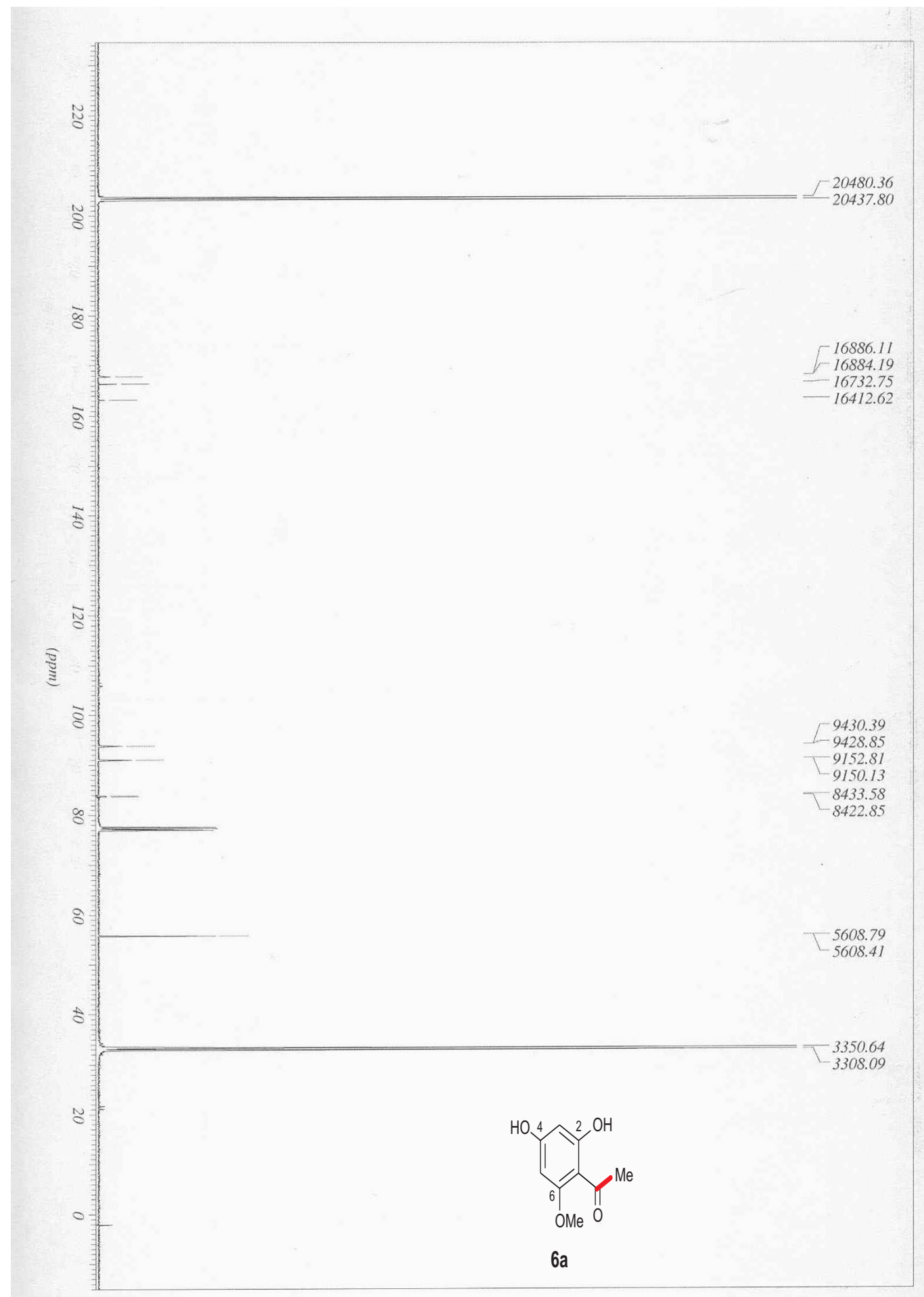

${ }^{13} \mathrm{C}$ NMR Spectrum of $\mathbf{6 a}$. 

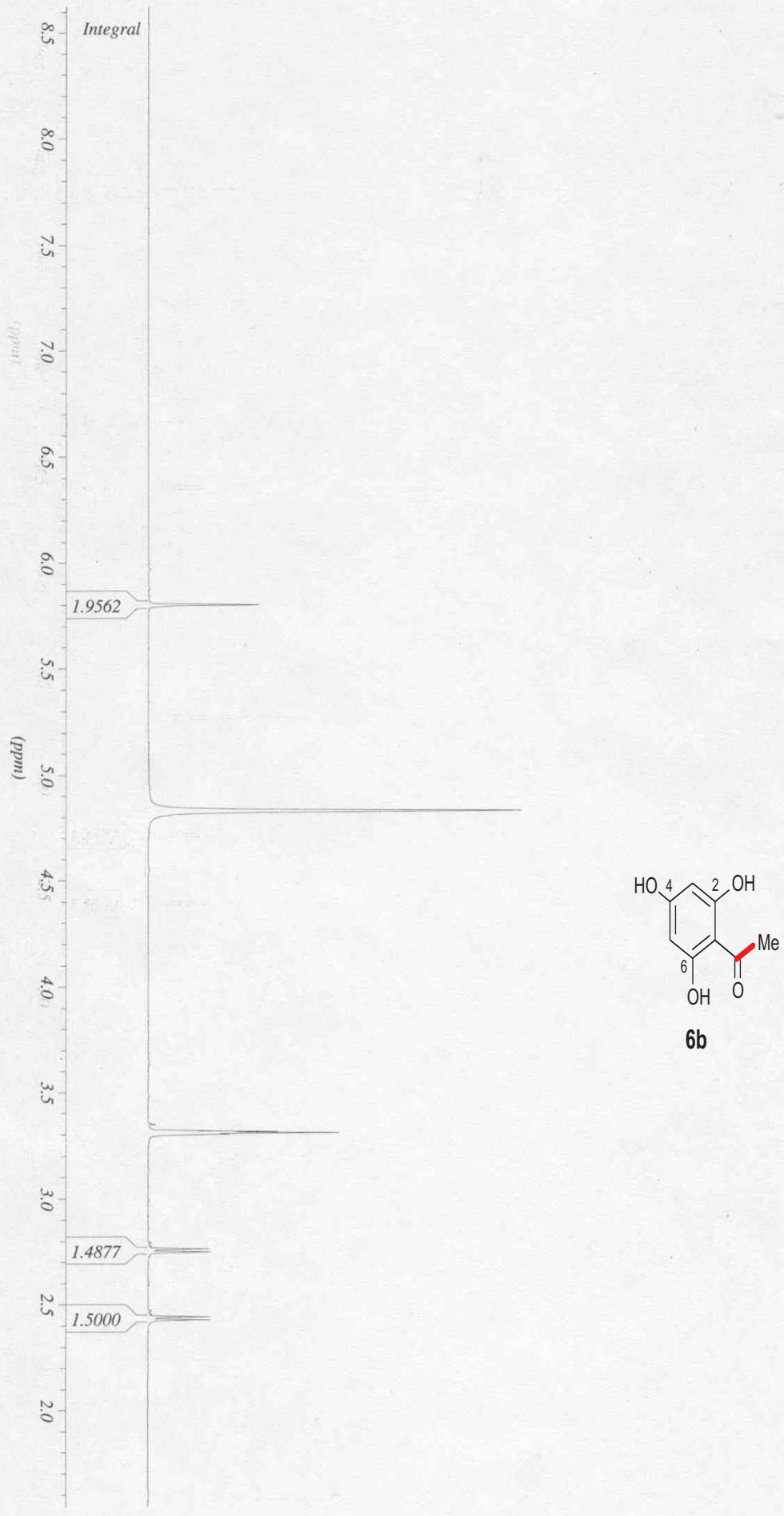

$6 b$

${ }^{1} \mathrm{H}$ NMR Spectrum of $\mathbf{6 b}$. 


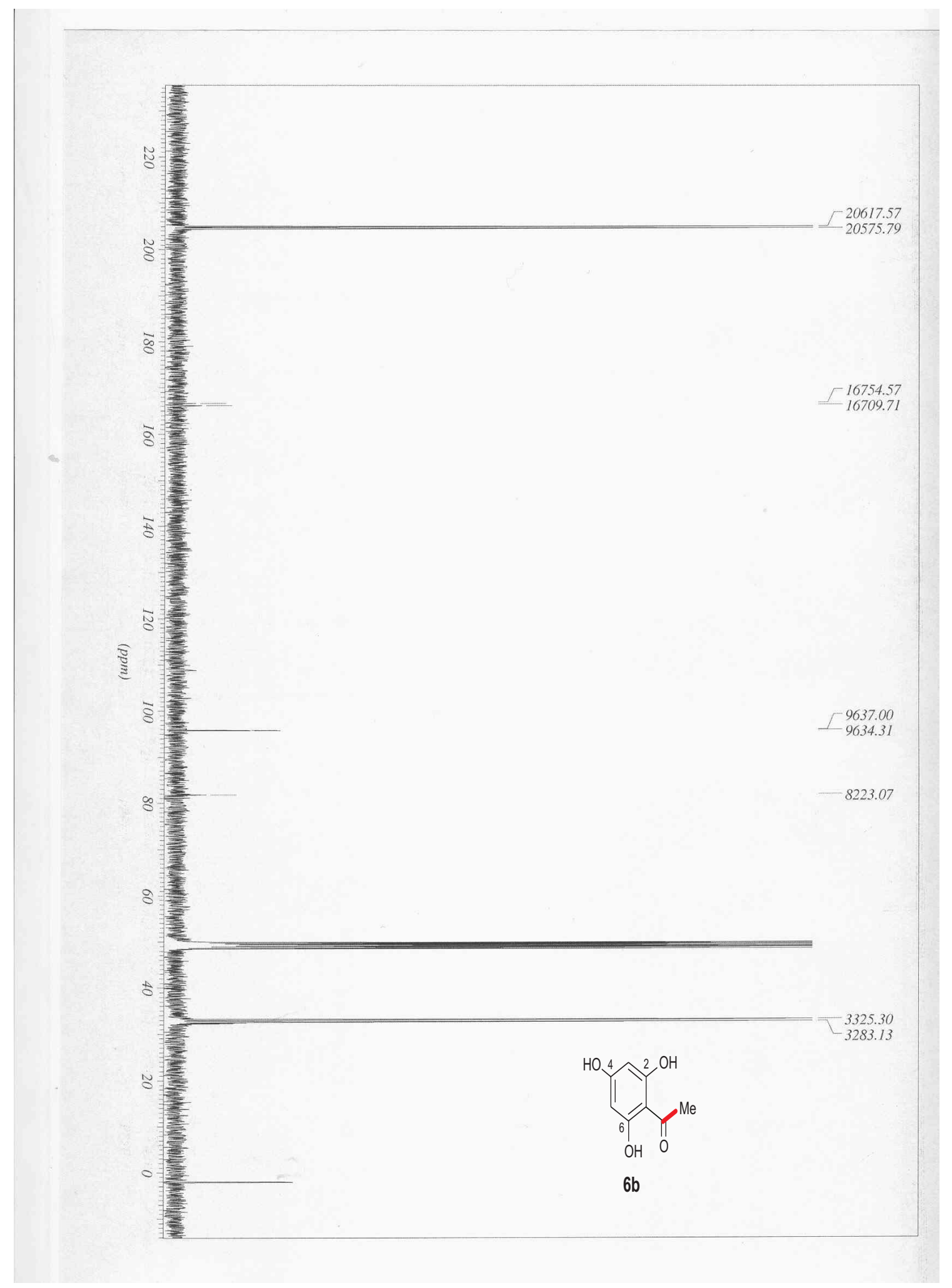

${ }^{13} \mathrm{C}$ NMR Spectrum of $\mathbf{6 b}$. 

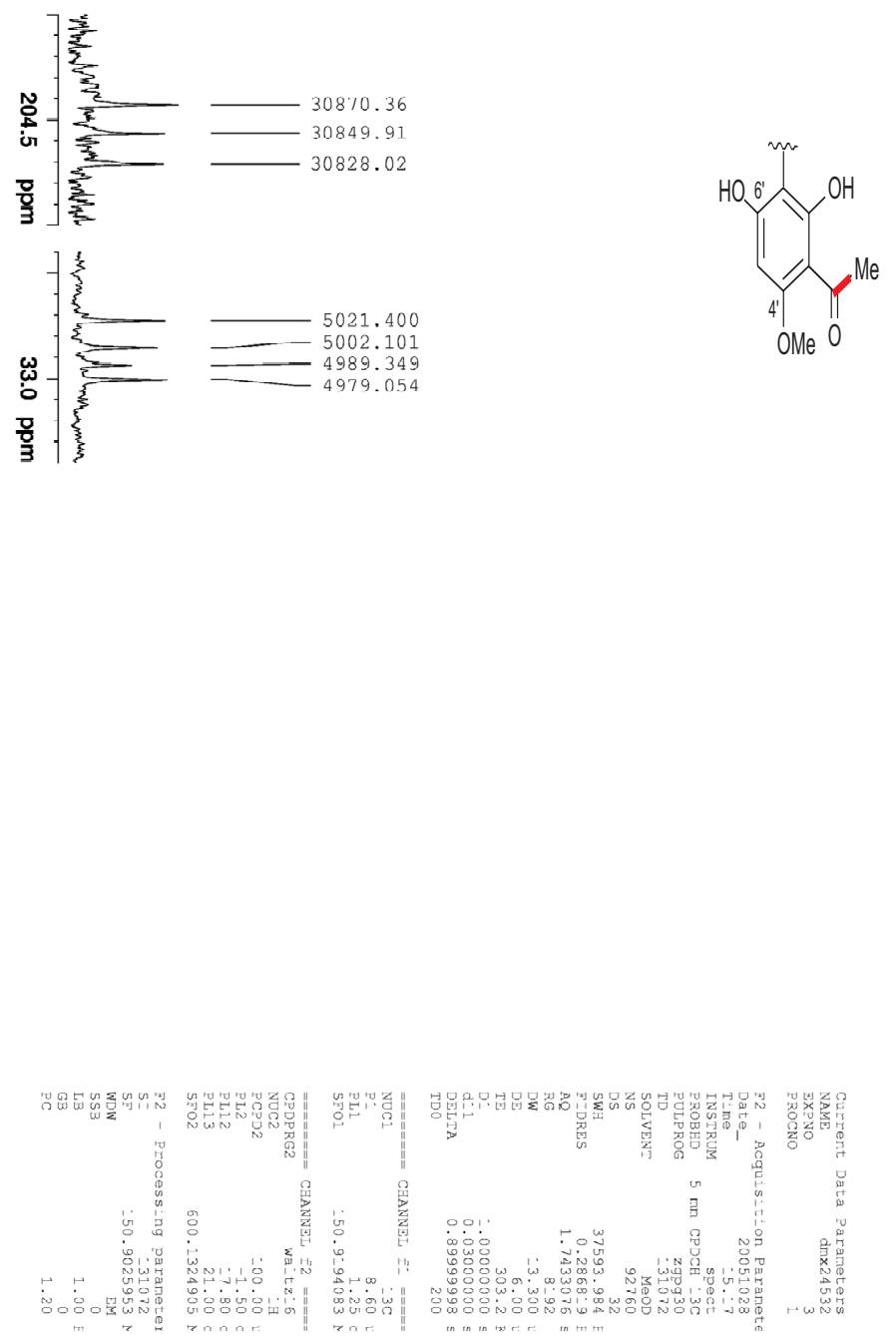

Sketches of the ${ }^{13} \mathrm{C}$ NMR Spectrum of Knipholone (4a) after Feeding of $\mathbf{6 a}$. 